Cite as: Bozan, K., \& Datta, P. (2016). The effect of perceived expected satisfaction with electronic health records availability on expected satisfaction with electronic health records portability in a multi-stakeholder environment. Interdisciplinary Journal of Information, Knowledge, and Management, 11, 31-53. Retrieved from http://www.informingscience.org/Publications/3434

\title{
The Effect of Perceived Expected Satisfaction with Electronic Health Records Availability on Expected Satisfaction with Electronic Health Records Portability in a Multi-Stakeholder Environment
}

\author{
Karoly Bozan \\ Idaho State University, \\ Pocatello, Idaho, USA
}

bozakaro@isu.edu

\author{
Pratim Datta \\ Kent State University, \\ Kent, Ohio, USA
}

pdatta@kent.edu

\begin{abstract}
A central premise for the creation of Electronic Health Records (EHR) is ensuring the portability of patient health records across various clinical, insurance, and regulatory entities. From portability standards such as International Classification of Diseases (ICD) to data sharing across institutions, a lack of portability of health data can jeopardize optimal care and reduce meaningful use. This research empirically investigates the relationship between health records availability and portability. Using data collected from 168 medical providers and patients, we confirm the positive relationship between user perceptions of expected satisfaction with EHR availability and the expected satisfaction with portability. Our findings contribute to more informed practice by understanding how ensuring the availability of patient data by virtue of enhanced data sharing standards, device independence, and better EHR data integration can subsequently drive perceptions of portability across a multitude of stakeholders.
\end{abstract}

Keywords: Design Theory, Data Availability, Data Portability, Satisfaction, Stakeholders, Patient Care Processes.

\section{Introduction}

Electronic Health Records (EHR) are the digitized longitudinal health records of an individual that are shared across agencies and providers. The success of an EHR system implementation is measured by the degree it is used (e.g., Devaraj \& Kohli, 2003) as an indicator that the system

Material published as part of this publication, either on-line or in print, is copyrighted by the Informing Science Institute. Permission to make digital or paper copy of part or all of these works for personal or classroom use is granted without fee provided that the copies are not made or distributed for profit or commercial advantage AND that copies 1) bear this notice in full and 2) give the full citation on the first page. It is permissible to abstract these works so long as credit is given. To copy in all other cases or to republish or to post on a server or to redistribute to lists requires specific permission and payment of a fee. Contact Publisher@,InformingScience.org to request redistribution permission. meets the users' expectations. Based on this principle, the Medicare, Medicaid incentive program is centered on the "Meaningful Use" of EHR systems. This program is aimed at ensuring that the certain EHR system features are properly used to provide safe, quality care with reduced disparity and increased data portability. 
Meeting expectations is an especially challenging objective to attain in a multi-stakeholder environment, such as the health care industry. A common reason for IS implementation failures is that organizations decide on a technological solution without fully understanding the underlying processes and stakeholders' objectives (McGowan, Cusack, \& Poon, 2008; Sallas, Matthews, Watkins, \& Wiley-Patton 2007).

The need for an EHR system that delivers quality information timely, securely, and accurately across multiple health care provider systems is essential for delivering safe and quality care. Due to the nature of health care organizations' value chain, multiple stakeholders, whose system use and expectations may significantly differ, are involved in the information flow process (Joss \& Kogan, 1995; McGlynn, 1997). Fulfilling the varying information needs across stakeholders is one of the most significant expectations from an EHR system and a key indicator of satisfaction with such a system (Thornewill, Dwling, Cox, \& Esterhazy, 2011).

Patient health information availability is an important system characteristic to confidently make well-informed decisions during patient care. For this purpose, the timely and complete patient health records need to be available to the right person at the right time. Primary healthcare providers $(\mathrm{PCP})$ can make more educated decisions if more up-to-date information is available for them (Bates et al., 2001).

For the purposes of this study, in addition to data availability, we also consider system availability to perform essential job functions efficiently, as a precursor of system use (Laplante \& Ovas$\mathrm{ka}, 2011)$. System availability is the extent to which goals are achieved with effectiveness, efficiency, and a level of satisfaction. However, when different user groups use the same system in different contexts, it is expected that these groups perceive the same system and particular features differently (Burn \& Ash, 2005).

Information systems may be used in different environments and on different platforms for the same functional purposes. Information sharing and the need for up-to-date information in the healthcare environment have always been demanded but only in the recent years have started to become a reality. The proper design and implementation of information sharing system characteristics will result in patient record portability. In order to reduce design and development costs, using the same source-code is inevitable for a portable system. System designers need to account for the disparate health data from the nation's many healthcare organizations. This will enable providers to universally exchange and reuse operational and clinical data stored in different EHR systems.

The multi-stakeholder context in this study represents the challenges the literature identifies for proper information systems design to fulfill varying user needs. The different user groups in different healthcare settings in this study are identified as 1) health care providers, 2) patients, 3 ) administrators, and 4) regulators within six major care providing agencies. Following Shi and Singh (2008) for our purposes, these are 1) hospital based outpatient care, 2) continuing care, 3) end-of-life-care, 4) preventative care, 5) primary care, and 6) rehabilitative services.

The objective of this study is to investigate the relationship between user perceptions of expected satisfaction with EHR data availability and the expected satisfaction with portability. Using data collected from 168 users across the identified four stakeholders groups among the major care providing agencies, empirical evidence is provided for the effect of perceived expected satisfaction with EHR availability on expected satisfaction with EHR portability. The availability and portability constructs were measured by reflective indicators and AMOS software for Structural Equation Modeling (SEM) was used to test our hypothesis. Both constructs have multiple indicators as it was deduced from the survey items. 
This paper aims to contribute to the existing research and gaps in knowledge management by providing a better understanding of information availability and portability among different stakeholder groups in the healthcare domain. The findings also highlight important practical implications and contribute to the knowledge management of software vendors, implementation project teams, and healthcare agency executives. These theoretical and practical contributions are discussed in detail in the discussion section.

The literature review is followed by the framework development and research methodology, then the results are discussed and the limitations and future directions are introduced.

\section{Literature Review}

Numerous studies have proved that satisfaction of system users is a key component to IS success (Al-Khaldi \& Wallace, 1999; DeLone \& McLean, 1992; Szajna \& Scamell, 1993). End user satisfaction is also suggested to be a deciding factor on software choice with relatively similar features (Henderson, Smith, Podd, \& Varela-Alvarez, 1995). Measuring satisfaction includes subjective measures such as the user's individual perception on usability and acceptability: "the comfort and acceptability of the work system to its users and other people affected by its use" (ISO DIS 9241210, 2008).

User satisfaction in a healthcare setting is imperative for implementation success (Meijden, Tange, Troost, \& Hasman, 2003; Murff \& Kannry, 2001) and failures are often associated with unsatisfied users (Lawler, Cacy, Viviani, Hamm, \& Cobb, 1996). EHR often replaces paper and pencil PCP notes, which requires an enormous adjustment within the new workflow of care. Many healthcare professionals view this change as obstruction to their work and decreased productivity (Chin \& Krall, 1997; Chin \& McClure, 1995; Tierney, Miller, Overhage, \& McDonald, 1993). This disruption is difficult to overcome in a high-pressure workplace, where time is a scarce resource and a new EHR system may be perceived as inefficient.

Providing the same system across multiple user groups across system characteristics is a challenging obstacle for system designers and implantation teams alike. The diverse stakeholder needs and use of EHR systems in a health care organization need to be understood and integrated in the system design meta-analysis. An EHR system that primarily supports subgroups of users may lead to decreased use and workarounds. Evidence for failed EHR implementations in the literature abound and numerous studies attribute the failures to unmet stakeholder needs (e.g., Aarts \& Peel, 1999; Berg, 2001; Bingi, Sharma, \& Godla, 1999; Zhang, Lee, Zhang, \& Banerjee, 2002). Other main reasons for such failures range from leadership disconnect, changed workflow, and work disruption to perceived inefficiency and decreased productivity, which ultimately results in partial or complete abandonment and rejection of the use of the EHR system by some or all users (Heeks, 2006; Kaplan \& Harris-Salamone, 2009; Simon, 2010).

Organizational information resources house enormous amounts of data, including sensitive customer and corporate information, especially in the healthcare industry (Fox, 2000). In addition to safeguarding this data from unauthorized access, availability of data is critical for sound decision making (Bakersville \& Siponen, 2002; David 2002). According to the Organisation for Economic Co-operation and Development (OECD), availability ensures the accessibility and usability of

data, information, and information systems on a timely basis in the required manner or simply the prevention of unauthorized withholding of data or resources (Dhillon \& Backhouse, 2001). The $44^{\text {th }}$ Code of Federal Regulations (U.S.C., Sec. 3542(b)(1)(A-C)) also includes the timely use of data in the definition of availability, which states, "ensuring timely and reliable access to and use of information". Availability is also used as one of the Security Objectives as part of the Standards for Security Categorization of Federal Information and Information Systems. 
Multi-stakeholder involvement in patient care requires data availability to a variety of functional groups. Patients recognize the value of information systems in primary care (Ornstein \& Bearden, 1994; Ridsdale \& Hudd, 1994); however, they express their worries about the availability of their health history to employees working in the system and the insurance companies.

Accordingly, this study aims to enhance the general understanding of EHR systems' data availability and portability features to support the multi-stakeholder needs across the patient care process. The next section introduces the framework constructs and their indicators as presented to the stakeholders to rate their perceived expected satisfaction.

\section{Framework}

The aim of this study is to identify the relationship between the perceived expected satisfaction with EHR data availability and the expected satisfaction with EHR data portability across different stakeholders. Following Walls, Widmeyer, and El Sawy's (1992) information system design theory (ISDT), availability and portability system features as meta-designs that support organizational requirements as meta-requirements were proposed to form the base of the system-level investigation of this study. A meta-analysis of other system features is covered in the Appendix, however, these features are beyond the scope of this paper.

The proposed model with the availability and portability constructs, their indicators, and the hypothesis with its suggested direction of effects is depicted in Figure 1. The professionals, to whom the survey was administered, were asked to base their experience on existing healthcare system features, not only on the particular Electronic Health Record (EHR) systems currently in use. The reason for this was twofold: (1) EHR systems are not widely implemented, it is the ultimate goal of the healthcare industry based on President Bush's Executive Order of 2004 (Executive Order 13335); (2) the term 'EHR system' is used to indicate any health information system.

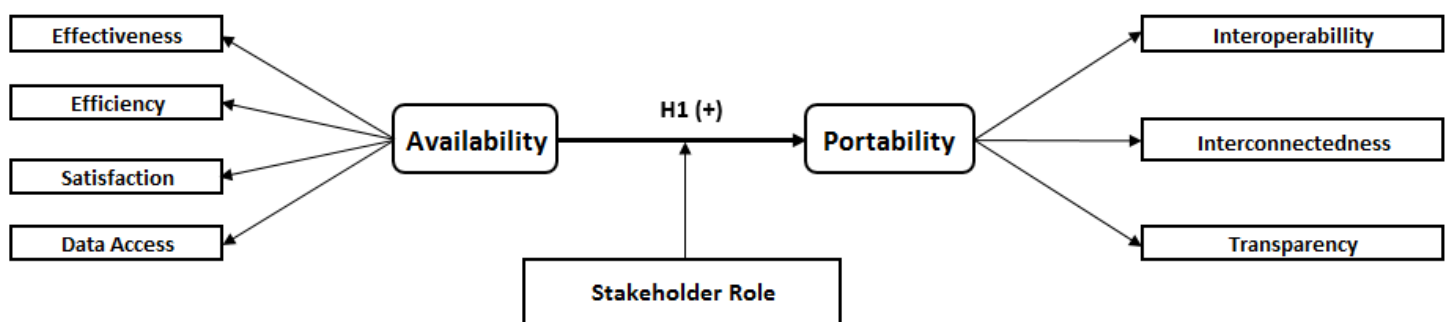

Figure 1. Research framework

\section{Availability Meta-Kernel}

Availability in this research is approached form two different angles: (1) the availability of information that enables users to make sound decisions, and (2) the availability of the system for the users to perform their job function in an effective and efficient manner. The first instance simply indicates user access to data required for decision making. The second instance overlaps with the concept of usability, where properly designed system needs to be available for proper access to the necessary information. In this concept we describe availability as the requirement for users to perform their job function with a system that meets their expectations for usability.

"Build it and they will come" is a phrase used to describe a utopian product development standpoint portraying the unnecessary effort of meeting user needs. Of course, it is rarely the case with information systems as the offering of technology continues to progress in a rapid rate. Users do not only expect an easy-to-learn and easy-to-use system, but they also expect that technology aids 
their productivity. Since we proposed applying usability as a subset of the availability metakernel, we will accept Dix, Finlay, Abowd, and Beale's (1993) and Nielsen's (1994) attributes of usability - effectiveness, efficiency, satisfaction, and learnability - for the purposes of this research. However, we will propose the first three concepts as part of availability meta-designs. We decided to not include learnability for two reasons: (1) it is highly subjective attribute and with a robust system such as EHR, resistance of change may be an influential factor that is difficult to account for when measuring a system's usability, (2) it is omitted in most technical definitions, such as Standard ISO 9241, which defines software usability as the following: a software is usable when it allows the user to execute his task effectively, efficiently, and with satisfaction in the specified context of use.

Our approach provides answers to the following questions with regards to usability attribute measurements:

- Effectiveness: How well can a user goal be achieved through the system use?

- Efficiency: What resources are consumed while achieving these goals?

- Satisfaction: How do users feel about the system they use to achieve their goal?

- Data Access: Is all information available for users to make a well informed, timely decision?

In our meta-designs, we recommend solutions to common healthcare system usability concerns, for example:

- Eliminating the need for duplicate entries by cross populating screens in problem lists and progress notes while checking for data validity.

- The system should easily allow visual integration of a problem with a particular clinical event (lab result, imaging, medication, etc.)

- Recording a new problem should follow logical steps and require minimal number of clicks while providing straightforward and familiar terminology and directions.

\section{Effectiveness}

Effectiveness as an attribute of usability is defined as "the accuracy and completeness with which specified users can achieve specified goals in particular environments" (ISO DIS 9241-210). In the context of information systems, we can define effectiveness as the degree to which an interface facilitates users in accomplishing their tasks and goals. This definition encompasses Hamilton and Chervany's (1981) goal centered view in regards to how well the objectives are achieved. They measure effectiveness on the use process and user performance. Effectiveness of an information system is also viewed as the precursor of system use and satisfaction (Bailey \& Pearson, 1983; Igbaria, 1990; Srinivasan, 1985). In an EHR system, effectiveness can be measured by the "success rate" or "task completion rate". For example, how well a new patient profile or lab order can be created in EHR is measured by the system effectiveness. Success rate measures the task accomplishment percentage, while task completion can be measured per unit. Success must be defined to establish benchmark for the system effectiveness, which affects usability. This could be a defined end point that needs to be reached, such as the confirmation page.

\section{Efficiency}

Efficiency refers to ratio of output divided by input and grew out of the economic discipline. Previous researches suggest that efficiency is a major part of usable and useful technology (Davis, 1989; 1993; Venkatesh, 2000; Venkatesh, Speier, \& Morris, 2002). The definition of efficiency identifies the rate or speed in addition to the effectiveness. The ISO definition emphasizes the resources needed for task completion: "the resources expended in relation to the accuracy and completeness of goals achieved". In addition to minimized resource, such as time, the consistency 
of responses is also an important measure of efficiency. These elements are also central to determine one's productivity; therefore, being efficient is necessary for being productive.

\section{Satisfaction}

Numerous studies have proved that satisfaction of system users is a key component to IS success (Al-Khaldi \& Wallace, 1999; DeLone \& McLean, 1992; Szajna \& Scamell, 1993). End user satisfaction is also suggested to be a deciding factor on software choice with relatively similar features (Henderson et al., 1995). Measuring satisfaction includes subjective measures such as the user's individual perception on usability and acceptability: "the comfort and acceptability of the work system to its users and other people affected by its use" (ISO 9241).

There are several software usability measures developed where users can input their subjective assessment on usability based on their satisfaction. The System Usability Scale (SUS) has received positive recognition and been applied by a number of researchers (Brooke, 1996; Lewis \& Sauro, 2009). Another such method is the Software Usability Measurement Inventory, which requires "Agree", "Don't Know", or "Disagree" input from users on 50 subjective statements.

\section{Data Access}

Literature identifies data access with the following attributes: accessible, retrievable, speed of access, available, up-to-date, and consistency (Kumar \& Segev, 1993; Panian, 2009). For the purposes of our research, we identify data access as an indicator for the availability construct. Users respond in regards to this indicator as their perceived level of expected satisfaction with relevant and up-to-date data they can retrieve and access with relative ease to make decision in terms of total data available that can be accessed with additional effort. Since time is of essence at making decisions during patient care, access to relevant and timely data is an important attribute of data availability.

\section{Portability Meta-kernel}

Information systems may be used in different environments and on different platforms for the same functional purposes. Information systems need to adapt to changing demands of their users through platform independence while allowing for shared operating processes. In a healthcare setting, real-time medical information should be shared across different platforms and systems, which is an extremely important design consideration for EHR systems. Based on the literature of the interoperability, interconnectedness, and transparency meta-kernels, we propose them as portability meta-kernel characteristics for system design.

\section{Interoperability}

Primary healthcare providers can make more educated decision if more up-to-date information is available for them (Bates et al., 2001). Information sharing and the need for up-to-date information in the healthcare environment have always been demanded, but only in the recent years have they started to become a reality. Enabling interoperability among healthcare systems and especially in EHR system is vital to achieve this system feature. Interoperability represents the ability of systems to exchange information for operational use (Institute of Electrical and Electronics Engineers [IEEE], 1990). Interoperability is defined by the International Organization for Standardizations (ISO) (ISO TC 215, ISO/TR 20514, 2005) as "the ability of two or more applications being able to communicate in an effective manner without compromising the content of the transmitted EHR". ISO's Technical Committee (TC) aims to ensure the standardization of Health Information and Communication Technology (ICT), to allow for interoperability and compatibility between independent systems. For our research, we define interoperability as the ability of an EHR system to connect with other systems in order to provide an EHR service. For 
example, the ability to connect with and receive real-time information from a public database of disease breakouts is vital for a healthcare institution. While access to such information might have been previously available, we argue the importance of this database to be connected directly to the EHR system to warn PCPs when identifiable symptoms are entered.

\section{Interconnectedness}

Systems interconnectivity offers benefits such as reduced operating cost, improved efficiency, greater functionality, and centralized data access. The National Institute of Standards and Technology (NIST) defines interconnectivity as the direct connection of two or more systems for the purpose of data and information resources sharing. For purposes of this research, interconnectedness is defined as the number of systems that are connected together with the EHR system to provide an EHR service. Providers often must make decisions without access to complete up-to-date patient health history, to which a connected EHR system have potential remedy (Kohn, Corrigan, \& Donaldson, 2000; Leape, Bates \& Culen, 1995).

\section{Transparency}

For purposes of this research, transparency is defined as the ability of a system to seamlessly integrate multiple system-level operations and processes such that a user does not feel that one or more independent systems and processes are interconnected to provide him or her a service. For example, a transparent EHR system can seamlessly integrate with multiple independent drugdatabases over the cloud and pull the information in real-time without the physician feeling a sense of lag or requiring separate sign-ons.

Multiple sources of information require the ability of a system to "translate" identifiers that are used for the record as aliases. System level design specifications need to include the system's ability to create, maintain, and provide a list of patient identifier cross reference entities. It will ensure that patient information will be properly referenced when requested in a different format. For example, laboratory services might know the patient record as an internal patient ID, however, when previous results are being queried from the data repository, the locator services indexed a previous ID, which was assigned by a different campus on a different system. Also, the patient might schedule an appointment using his or her social security number. These identifiers need to be cross referenced among each other in order to refer to the same patient.

Transparency ensures that multiple systems provide information while the user experiences a single-system use (Razi, Athappilly, \& Rea, 2009). In the background, however, information is queried and provided across multiple internal or external databases. If the user is not required to log into another system, we consider it highly transparent system integration. On the contrary, if a user is aware that he or she is being redirected to another system and in addition the user is required to separately $\log$ into this/these additional system/s, we consider that system integration low transparent.

\section{Hypothesis}

Information shared across different systems to support different job function is supported by the portability system characteristic (meta-kernel). Since data portability is a collective representation of different system features (meta-designs), such as interconnectivity and interconnectedness, and transparency (Bates et al. 2001), users expect that these features are represented to their expectation of satisfaction.

The safeguarding measures of patient medical information is crucial because of its considerable economic, social, and psychological harm to individuals if it is accessed by unauthorized party(ies) (Ancker, Edwards, \& Miller, 2012; Dimitropoulos, Patel, \& Cheffler, 2011). With distrib- 
uted health networks and patient care, pooling data into a central repository to increase data availability is an important part to support sound decision making for proper care (Bates et al., 2001). However, healthcare system users, who need this information quickly for proper diagnosis and treatment plan, are intolerant of cumbersome security measures to access the repository from their primary healthcare system. Therefore, data availability needs to come with a balance between providing the right information to the right person at the right time without the burden of multistep validation procedures across multiple information systems where the information is located.

Interconnected healthcare systems need to be interoperable with each other especially because of the multiple file format in which they store information. While front-end users do not experience the portability of the system they use directly, they assess portability based on data availability (Padhy, Patry, \& Satapathy, 2011).

In a healthcare organization, stakeholders may or may not be aware that the data they retrieve is pooled from internal or an external repository(ies). Satisfaction with data portability is directly related to data availability, since stakeholders measure their satisfaction based on whether or not they receive the required information (Radakrishna, Goud, Kasthuri, Waghmare, \& Raj, 2014). If users expect EHR data availability system characteristics to perform to their expected satisfaction, they associate this characteristic with data and system portability as well. Therefore, it is posited that increased expected satisfaction with data availability leads to increased expected satisfaction with data portability for stakeholders in a healthcare organization.

Hypothesis 1: Satisfaction with availability is positively associated with satisfaction with portability.

Dissatisfaction with a system characteristic impacts the use of the system. DeLone and McLean's widely cited work, the IS Success Model (1992) also confirms that system use is dependent on the satisfaction with the system. Therefore, if a system provides the required features to the expected satisfaction, a user group is more likely to use it. It is especially true if the user group is satisfied and the feature is important to support their job function.

\section{Methodology}

\section{Design of an Instrument}

The proposed design theoretical framework is built upon the previously introduced meta-kernels and meta-designs. In the methodology section, the meta-kernel is embedded into the metarequirements following information systems design theory as presented in Walls et al. (1992).

The system level characteristics will be aligned with the organizational level requirements. Then we empirically identify the system features that are loading under each system characteristic, using principal component method. That will confirm the proper system feature under the corresponding system characteristic our design-theoretic model based on the empirical data collected.

A review of the literature suggests that existing studies limit their attention to conflicting stakeholder interests (Ahn \& Skudlark, 1997; Oz \& Sosik, 2000; Pan, 2005), but these studies either lack empirical evidence or they focus on one particular process or stakeholder group (e.g., Greenhalgh et al., 2010). Therefore, health professionals representing four major stakeholder groups, (1) primary care providers, including nurses (PCP), (2) auditors, (3) administrators, and (4) patients, were surveyed on their perceived expected satisfaction with EHR data availability and perceived expected satisfaction with EHR data portability. The survey divided the patient-primary care provider encounter into four major process sequence blocks: (1) schedule and administer patient visit, (2) collect and review patient medical information, (3) diagnose and treat patient, and (4) report and follow up. The process sequence blocks were identified through a detailed re- 
view of patient care process from appointment scheduling to follow-up care. The activities, then, were categorized into the above four major sequence blocks, each of which were identified as different level of availability and portability needs across the stakeholder groups.

\section{Meta-Requirement}

Walls et al. (1992) suggest that meta-requirements should be formed in an abstracted fashion to support the design theory's purpose of solving a class of problems. Therefore, the metarequirements are still on the meta level, but inferred from the problem identified and guided by the solution objectives, to which the kernel theory is applied. For purposes of this research, we define meta-requirements as organizational level abstractions that characterize the design features. The organizational level is supported by user oriented representation of objectives without system oriented details given. It is the system designers' responsibility to tie in the appropriate system level class of artifacts that will meet these organizational level meta-requirements.

\section{Meta-Kernel}

The actual design of a class of artifacts directly supports the concepts identified in the metarequirements. For the purposes of this research, we define meta-kernel as a system and design oriented abstraction that defines a process and its embedded characteristics. Meta-kernels further clarify the system requirements to the developers and provide additional details to limit developers' options and therefore aim their attention to the requirements. The meta-kernels step in our proposed design-theoretic model is primarily concerned with the identification of the system characteristics that satisfy the organizational level meta-requirements identified in the previous model element. Evaluating the meta-requirements and the literature that supports their needs, we propose that EHR data availability and EHR data portability meta-kernels will satisfy their corresponding organizational level meta-requirements. Table 1 indicates the system level characteristics and organizational level requirements.

These meta-kernels represent system characteristics that encompass the processes that stakeholders perform during their job functions. For example, an administrator requires the system to assist the regulatory compliance efforts; therefore, the system must possess characteristics that support this requirement. It is important to note that meta-kernels do not describe the specific sets of features, but provide a class of possible features that need to be evaluated based on user needs.

Table 1. Meta-kernel and meta-requirement of the design-theoretic model

\begin{tabular}{|l|l|}
\hline Meta-Kernel & Meta-Requirement \\
\hline The system characteristics of: & Means that the system should: \\
\hline Availability & Support user work function in an effective and efficient manner \\
\hline Portability & $\begin{array}{l}\text { Account for the disparate health data frm the nation's many } \\
\text { healthcare organizations and providers and enable the universal } \\
\text { exchange and reuse of operational clinical data stored in } \\
\text { different EHR systems. }\end{array}$ \\
\hline
\end{tabular}

\section{Data Collection}

An online survey was conducted to investigate the relationship between data availability and portability and their relationship to satisfaction with an EHR system. This relationship was scrutinized across multiple stakeholder groups. Following Walls et al.'s (1992) information system design theory (ISDT), this study proposes seven system features as meta-designs that support four organizational requirements as meta-requirements. These seven meta-designs were presented to 
survey respondents, and they were asked their perceptions of expected satisfaction with each system features.

\section{Population selection}

Survey respondents were recruited by two methods: (1) cold callings, (2) personal contacts that represented each stakeholder group were asked to recruit colleagues within and outside of their organization. Convenient sampling approach was followed from mainly outpatient health care facilities across the United States. Thus, 168 professionals representing all four previously identified stakeholder groups across six different healthcare institutions (as suggested by Shi \& Singh, 2008) responded to the survey. Figure 2 and Figure 3 demonstrate the response rate by role and region and role and institution.

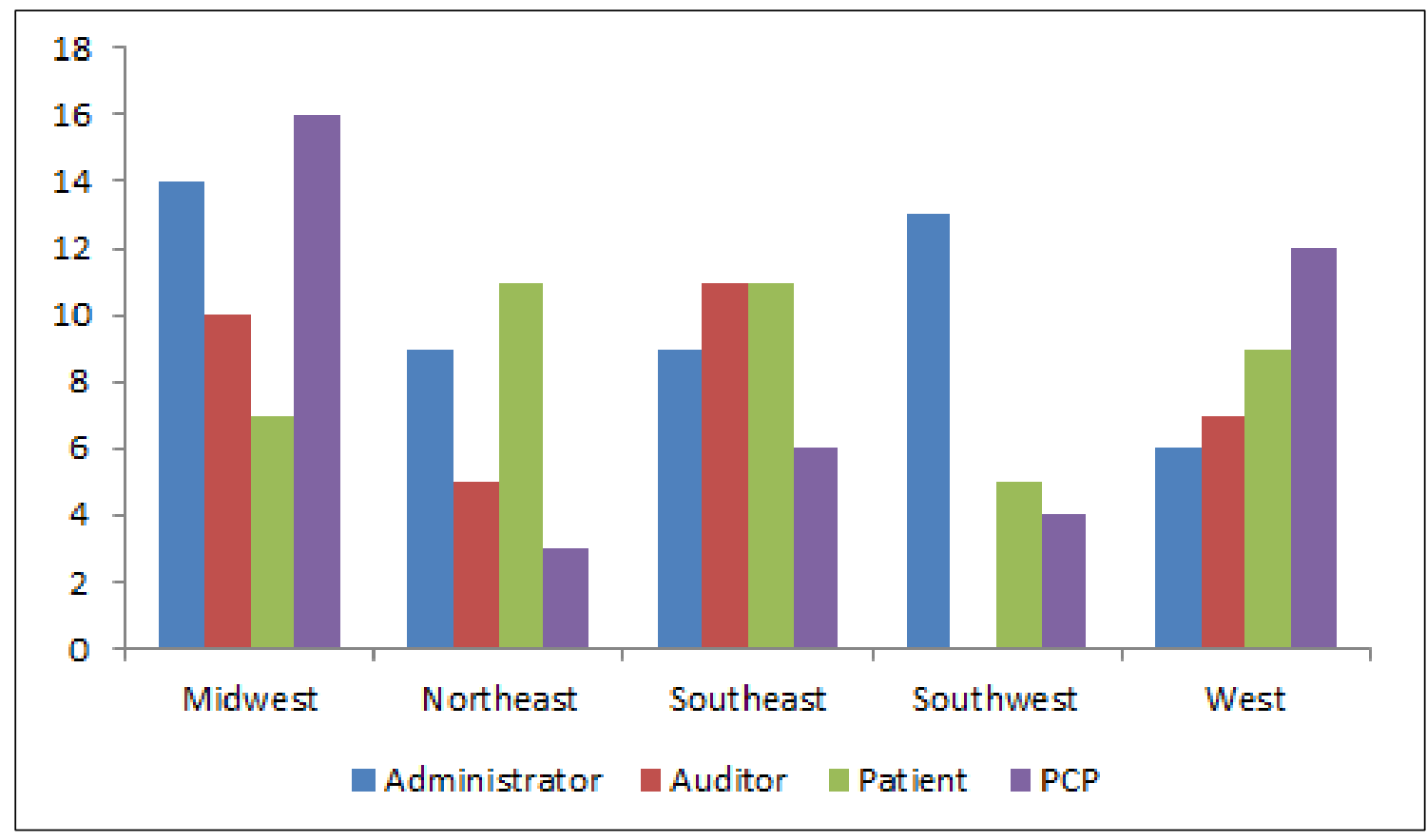

\begin{tabular}{|l|c|c|c|c|c|c|}
\hline Healthcare Role & Midwest & Northeast & Southeast & Southwest & West & Total \\
\hline Administrator & 14 & 9 & 9 & 13 & 5 & 50 \\
Auditor & 11 & 5 & 11 & & 7 & 34 \\
Patient & 7 & 11 & 11 & 5 & 9 & 43 \\
PCP & 16 & 3 & 6 & 4 & 12 & 41 \\
\hline Total & 48 & 28 & 37 & 22 & 33 & 168 \\
\hline
\end{tabular}

Figure 2. Survey response rate by region and role

In this research the constructs were measured by reflective indicators and AMOS software for Structural Equation Modeling (SEM) was used to test the hypothesis. All constructs have multiple indicators as it was deduced from the survey items earlier.

Model Fit: Unstandardized estimates were used as recommended for variables with unequal variance (Kline, 2010) and the Levene's test failed to confirm the null hypothesis that states that the groups have equal variances. Composite reliability and average variance extracted cannot be dependably computed as those values use standardized values. Statistical significance, chi-square values significance and root-mean-square error of approximation along with GFI were examined to ensure that the data fits the proposed model. 


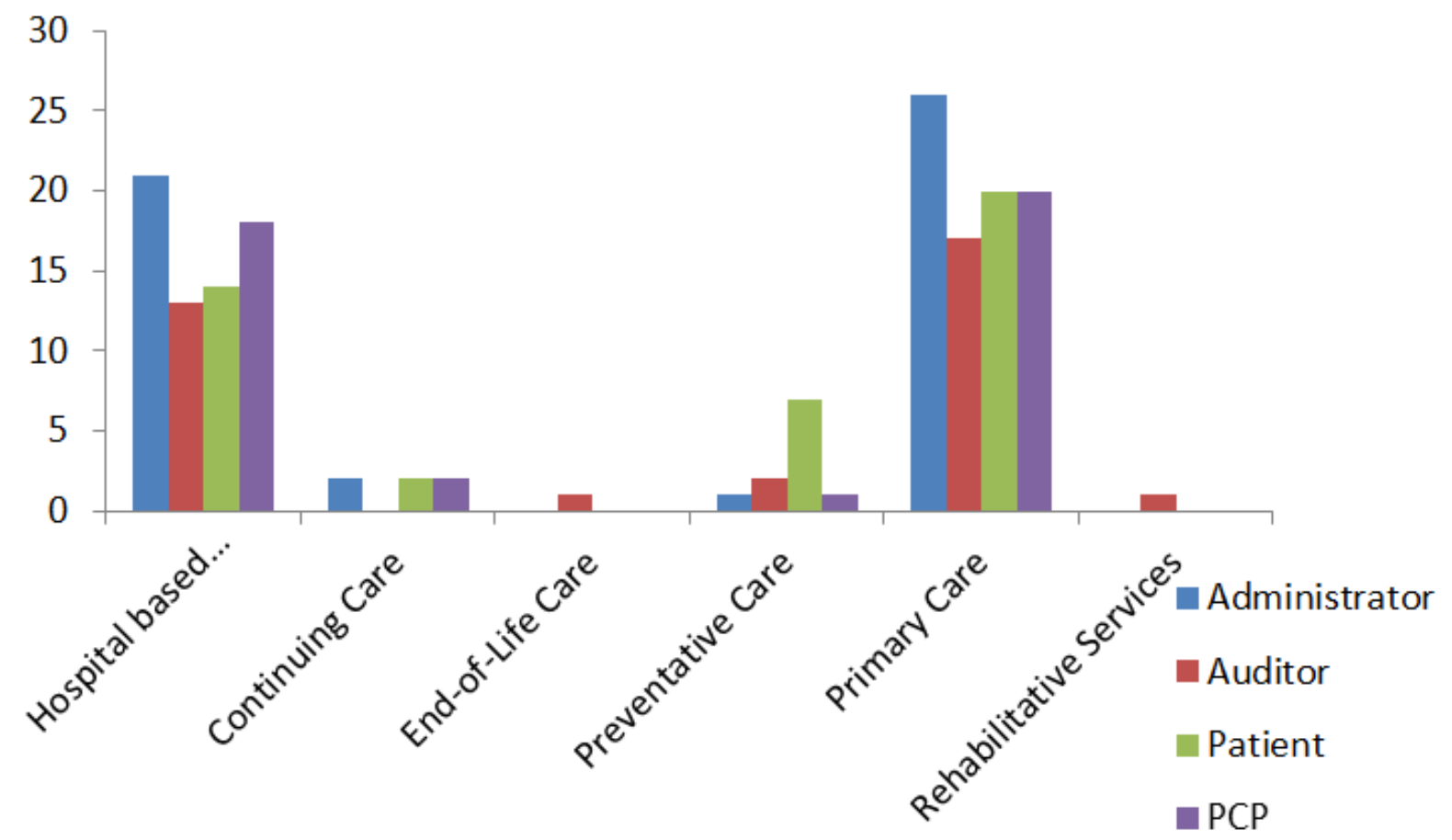

\begin{tabular}{|l|c|c|c|c|c|c|c|}
\hline Healthcare Role & $\begin{array}{c}\text { Hospital based } \\
\text { outpatient care }\end{array}$ & $\begin{array}{c}\text { Continuing } \\
\text { Care }\end{array}$ & $\begin{array}{c}\text { End-of-Life } \\
\text { Care }\end{array}$ & $\begin{array}{c}\text { Preventative } \\
\text { Care }\end{array}$ & Primary Care & $\begin{array}{c}\text { Rehabilitative } \\
\text { Services }\end{array}$ & Total \\
\hline Administrator & 21 & 2 & & 1 & 26 & & 51 \\
Auditor & 13 & & 1 & 2 & 17 & 1 & 33 \\
Patient & 14 & 2 & & 7 & 20 & & 43 \\
PCP & 18 & 2 & & 1 & 20 & & 41 \\
\hline Total & $\mathbf{6 6}$ & $\mathbf{6}$ & $\mathbf{1}$ & $\mathbf{1 1}$ & $\mathbf{8 3}$ & $\mathbf{1}$ & $\mathbf{1 6 8}$ \\
\hline
\end{tabular}

Figure 3. Survey response rate by role and healthcare institution

\section{Data reduction and validity check}

Respondents were asked to identify their perception of expected satisfaction with healthcare system features across patient flow processes. The construct indicators included the meta-designs listed earlier across the four patient flow processes. Factor analysis was utilized using SPSS version 22 for Windows to identify the "intercorrelated" observed indicators, which load under a common factor (Field, 2000, p. 424). Principal component analysis (PCA) method was employed to extract the factors and followed with a varimax (orthogonal) rotation (Gorsuch, 1983, p. 205).

The interrelationship among variables is best studied through factor analysis, which includes a variety of correlational analyses (Carr, 1992; Gorsuch, 1983).

When testing for multicollinearity, the Bartlett's test of sphericity $\left(\chi^{2}(55)=881.13, p<0.001\right)$ was used, which indicated that principal component analysis (PCA) was adequate for the data, the correlation matrix, in fact, is not an identity matrix . The Kaiser-Myer-Olkin (KMO) measure of sampling adequacy is a high value of 0.858 . This indicates that the data will factor well as the items will be able to be grouped into a smaller set of underlying factors.

The indicators were extracted into two factors, which represented availability and portability meta-kernels. Factors with scores of $>\sim 0.6$ were retained in accordance with Hair, Black, Babin, \& Anderson (2010). The reliability statistics (Cronbach's alpha) is 0.866 , which indicates a high 
level of internal consistency for the scale and exceeds the recommended 0.7 value (DeVellis, 2003; Kline, 2005).

Construct validity evidence of self-reporting expected satisfaction with meta-kernels is supported as items loaded together measuring the same constructs, labeled as availability and portability (see Table 2).

Table 2. Item loadings

\begin{tabular}{|l|l|c|c|}
\hline \multirow{2}{*}{ Observed Indicators } & \multicolumn{2}{|c|}{ Care Process } & \multicolumn{2}{|c|}{ Factors } \\
\cline { 3 - 4 } & & Availability & Portability \\
\hline Data Access & Coll/Rev Pat Med History & 0.706 & \\
Data Access & Diagnose \& Treat Patient & 0.686 & \\
Data Access & Report \& Follow Up & 0.593 & \\
Efficiency & Diagnose \& Treat Patient & 0.673 & \\
\hline Interconnectedness & Sch./ Adm. Patient Visit & & 0.619 \\
Interconnectedness & Coll/Rev Pat Med History & & 0.613 \\
Interconnectedness & Diagnose \& Treat Patient & & 0.617 \\
Interconnectedness & Report \& Follow Up & & 0.591 \\
Interoperability & Sch./ Adm. Patient Visit & & 0.673 \\
Interoperability & Coll/Rev Pat Med History & & 0.668 \\
Interoperability & Diagnose \& Treat Patient & & 0.624 \\
\hline
\end{tabular}

A scree test and eigenvalues also suggested the above factors with face validity. Four items loaded in the first factor and seven on the second factor, labeled after the meta-kernel availability and portability, on which the conjointly loaded items suggested to measure the perceived expected satisfaction.

The first factor labeled availability and the following four factor indicators loaded on it: (1) data availability during reviewing patient medical history, diagnosing and treating patient, and reporting and follow up processes; (2) efficiency during diagnosing and treating patient flow process.

Seven items loaded on the second factor and labeled portability due to the communality in its factor indicators: (1) interconnectedness during all four patient flow processes, and (2) interoperability during reviewing patient medical information, diagnosing and treating patient, and reporting and follow-up processes.

\section{Results}

\section{Model Across all Stakeholders}

The path estimates are displayed and the critical ratios are statistically significant $(\mathrm{P}<0.001)$ in the measurement model of the independent variables. The items to keep in the measurement model were deduced earlier in this research. Figure 4 extends Figure 1 and visually displays the indicator estimate loadings and the path estimate between availability and portability constructs. 


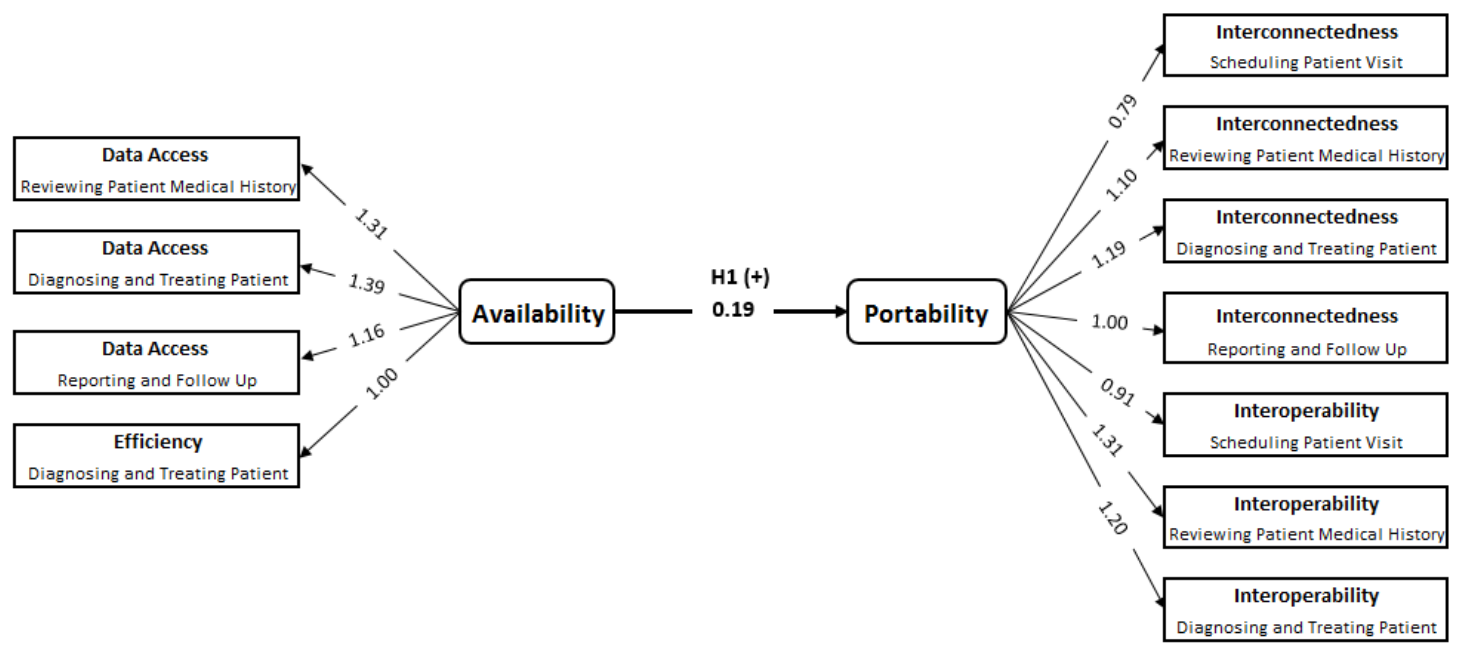

Figure 4. Estimate loadings in the framework

Table 3 displays the estimate loadings of the constructs indicators in the measurement model along with standard error, critical ratio, and p-value.

Table 3. Estimate loadings of the indicators in the measurement model

\begin{tabular}{|c|c|c|c|c|c|c|}
\hline \multirow[b]{2}{*}{ Constructs } & \multirow[b]{2}{*}{ Indicators } & \multirow[b]{2}{*}{ Patient Flow Process } & \multicolumn{4}{|c|}{ Maximum Likelihood Estimates } \\
\hline & & & Estimates & S.E. & C.R. & $\mathbf{P}$ \\
\hline \multirow{4}{*}{ Availability } & Data Access & Reviewing Patient Medical History & 1.306 & 0.226 & 5.776 & **** \\
\hline & Data Access & Diagnosing and Treating Patient & 1.385 & 0.233 & 5.942 & *** \\
\hline & Data Access & Reporting and Follow Up & 1.162 & 0.211 & 5.514 & $* * *$ \\
\hline & Efficiency & Diagnosing and Treating Patient & 1.000 & \multicolumn{3}{|c|}{ Fixed Regression Weight } \\
\hline \multirow{7}{*}{ Portability } & Interconnectedness & Scheduling Patient Visit & 0.790 & 0.171 & 4.615 & $* * *$ \\
\hline & Interconnectedness & Reviewing Patient Medical History & 1.102 & 0.189 & 5.846 & *** \\
\hline & Interconnectedness & Diagnosing and Treating Patient & 1.192 & 0.195 & 6.114 & $* * *$ \\
\hline & Interconnectedness & Reporting and Follow Up & 1.000 & \multicolumn{3}{|c|}{ Fixed Regression Weight } \\
\hline & Interoperability & Scheduling Patient Visit & 0.906 & 0.180 & 5.023 & *** \\
\hline & Interoperability & Reviewing Patient Medical History & 1.310 & 0.213 & 6.140 & $* * *$ \\
\hline & Interoperability & Diagnosing and Treating Patient & 1.195 & 0.198 & 6.022 & $* * *$ \\
\hline
\end{tabular}

S.E. Standard Error C.R. Critical Ratio

Satisfaction with availability of existing healthcare systems is best indicated by data availability during diagnosis and treatment, and reviewing patient medical history. It is in line with the expectations of "the right information at the right time for the right person" as indicated by the other two constructs' factor loadings. Stakeholders collectively expect that a system has data available during the review of patient medical history and diagnosis and treatment, but are not satisfied with the current feature in existing information systems.

Satisfaction with portability of existing healthcare systems is best indicated by interoperability during the patient medical history review process and interconnectedness during the same patient flow process. This indicates that stakeholders find the meta-design of a system most important during diagnosis and treatment in regard to system portability. The dependence of data availability is clearly explained by the fact that relevant medical information during diagnosis and treatment is inevitable through interconnected systems and stakeholders expect more in regards to this meta-kernel. 


\section{Structural model estimate loadings of the latent (unobserved) variables}

The path estimates of the latent variables loaded statistically significantly $(p<0.05)$. The associations of the latent variables are indicated through the estimates direction and magnitude. The loadings supported the hypothesis and Table 4 provides a summary of the estimate loadings.

Table 4. Estimate loadings of the constructs in the structural model

\begin{tabular}{|c|c|c|c|c|}
\hline \multirow[b]{2}{*}{ Constructs } & \multicolumn{4}{|c|}{ Maximum Likelihood Estimates } \\
\hline & Estimates & S.E. & C.R. & $\mathbf{P}$ \\
\hline Availability $\Longrightarrow$ Portability & 0.186 & 0.091 & 2.052 & 0.04 \\
\hline
\end{tabular}

\section{Stakeholder Role as Moderator for Hypothesis}

The overall model exhibited a proper fit (GFI $>0.9)$ and the estimates were statistically significant $(\mathrm{P}<0.001)$. Perceived expected satisfaction with availability of existing healthcare systems is positively associated with perceived expected satisfaction with portability of existing healthcare systems is confirmed with a factor loading of 0.22 . Table 5 displays the highest factor loadings (highlighted) for all stakeholders collectively and for each stakeholder separately.

The highest factor loading for perceived expected satisfaction with availability of existing healthcare systems have a variation across stakeholder groups. While patients and administrators exhibit interconnectedness during diagnosing and treating patient process as the most important indicator, PCPs find interoperability during reviewing patient medical history to be the best indicator of perceived expected satisfaction with portability of an existing healthcare system. This indicator is also the best for across all stakeholder groups. Auditors find interconnectedness to be the best indicator during the same process.

Table 5: The moderation effect of stakeholder role on the relationship between portability and availability

\begin{tabular}{|c|c|c|c|c|c|c|c|}
\hline \multicolumn{3}{|c|}{$\begin{array}{l}\text { H1 - Satisfaction with availability is positively associated with satisfaction with } \\
\text { portability. }\end{array}$} & $\begin{array}{c}\text { All } \\
\text { stakeholders }\end{array}$ & Patients & PCP's & Admins & Auditors \\
\hline Constructs & Indicators & \begin{tabular}{|l} 
Patient Flow Process \\
\end{tabular} & \multicolumn{5}{|c|}{ Estimates } \\
\hline \multirow[t]{7}{*}{ Portability } & Interconnectedness & Scheduling patient visit & 0.67 & 0.22 & 0.35 & 0.62 & 0.65 \\
\hline & Interconnectedness & Reviewing patient medical history & 0.94 & 0.84 & 0.24 & 0.91 & 1.61 \\
\hline & Interconnectedness & Diagnosing and treating patient & 1.03 & 0.96 & 0.38 & 1.64 & 1.55 \\
\hline & Interconnectedness & Reporting and follow-up & 0.87 & 0.83 & 0.39 & 0.99 & 0.54 \\
\hline & Interoperability & Scheduling patient visit & 0.77 & 0.46 & 0.73 & 0.79 & 0.72 \\
\hline & Interoperability & Reviewing patient medical history & 1.09 & 0.94 & 1.44 & 0.85 & 1.15 \\
\hline & Interoperability & Diagnosing and treating patient & 1 & 1 & 1 & 1 & 1 \\
\hline \multirow[t]{4}{*}{ Availability } & Data Availability & Reviewing patient medical history & 1.31 & 2.54 & 1.45 & 1.22 & 1.27 \\
\hline & Data Availability & Diagnosing and treating patient & 1.38 & 2.93 & 1.34 & 1.68 & 0.62 \\
\hline & Data Availability & Reporting and follow-up & 1.16 & 2.02 & 1.24 & 1.37 & 1.23 \\
\hline & Efficiency & Diagnosing and treating patient & 1 & 1 & 1 & 1 & 1 \\
\hline \multicolumn{3}{|c|}{ Availability $\rightarrow$ Portability } & 0.22 & 1.59 & 0.06 & 0.29 & 0.41 \\
\hline
\end{tabular}

While there is a degree of variation regarding the highest estimates across stakeholder groups, the direction of path coefficients stayed the same, therefore, indicating positive association between perceived expected satisfaction with availability of existing healthcare systems and perceived expected satisfaction with portability of existing healthcare systems. Patients exhibited the strongest path coefficient and PCP's the weakest. This signals that patients feel better cared for if all of their medical history is accessible and available at the time of their care, while PCPs seem not to 
associate data availability with system portability that closely. They seem to trust the internally available data and not rely on external accessibility.

It could be grounds of further investigation why PCPs don't correlate data availability with connectivity with other systems.

\section{Model fit}

The root-mean-square error of approximation (RMSEA) is 0.67 which is above the recommended 0.05 (Browne \& Cudeck, 1993) and indicates an acceptable error of approximation. The goodness of fit (GFI) is 0.853, which is above the recommended 0.8 value (Baumgartner \& Hombur, 1996), and also above the permissible level of 0.7 in certain model complexity and sample size combinations (Hair, Anderson, Tatham, \& Black, 1998). The Chi-square test yields a value of $\chi^{2}=686.7$ $(\mathrm{df}=345), \mathrm{P}<0.001$, which does not reject the null hypothesis of an overall good fit.

\section{Discussion}

Care delivery in the healthcare industry involves conflicting viewpoints of users (Ahn \& Skudlark, 1997; Oz \& Sosik, 2000; Pan, 2005) and the support of collaborating inter-professional teams, practice administrators, patients, and practice auditors. Consequently, designing a system that supports all stakeholders' expectations has been a challenging task. After reviewing the use of clinical information systems and identifying their functions, Dorr, Jones, and Wilcox (2007) concluded that electronic health records systems lack the multi-stakeholder support. Aligning the IS with users' varying need, therefore, becomes more difficult (Corvera Charaf, Rosenkranz, \& Holten, 2013, Vaast \& Levina, 2006) and results in a more complex system deployment (Bergman, Beyth-Marom, \& Nachmias 2008). Therefore, the system features need to follow a rigorous system design methodology that accounts for the varying need of the stakeholders and the benefit they seek across their job functions. It is especially important in the context of EHR, where the same feature might be perceived differently based on users' need and the function it supports.

Existing literature focuses on a single user group or process (e.g. Greenhalgh et al., 2010), therefore, the need emerges to consider the multi-stakeholder view across different organizational processes. The current study empirically investigates how perceived expected satisfaction with EHR data availability is related to perceived expected satisfaction with EHR data portability in the healthcare domain. The findings can have important practical implications for software vendors and software users and their management.

Different stakeholder groups perceive the system characteristics differently and their perceived satisfaction varies based on the care process. For example, availability of patient health information decreases the needs to duplicate lab works in case patients visit a PCP outside of their previous provider's network. This eliminates unnecessary financial and time burden for the patients. PCPs can bring confident decisions and EHR can ensure that PCPs who are involved in a patient's care base their decisions on uniform sets of data. Administrators need to ensure that the care organization's EHR system has the up-to-date patient information at the time of patient care and that it is traceable for compliance purposes. In addition, a healthcare organization's administrator needs to put forward the required safety measures to ensure that patient information entered at the place of care is only accessible by PCPs who are part of the continued care, besides emergency circumstances. Auditors need to be able to audit the system for safeguard measures concerning patient health information communication with only the required providers. Ensuring proper data availability may require implementing measures such as authentication and interoperability checks and data standards implementation.

We followed Walls et al.'s (1992) ISDT to identify meta-kernels that align with organizational meta-requirements in the data availability and portability system characteristics. Following the 
literature, we measured perceived satisfaction with EHR availability through effectiveness, efficiency, satisfaction, and data access. Using Principal Component Analysis, only data access and efficiency loaded together as indicators of availability. The estimate loadings indicated that EHR data and availability is best measured by efficiency and data access. Data access during the diagnosis and patient treatment process proved to be the strongest indicator followed closely by data access during reviewing patient medical history. These findings contribute to the literature as they identify the patient care process on a more granular level and pinpoint the processes and system characteristics with which stakeholders were expected to be more satisfied in order to deliver quality care.

Similarly, we identified the indicators of EHR data portability following the literature: interconnectedness, interoperability, and transparency. Primary healthcare providers indicated that interoperability and interconnectedness across most process during patient care best load together to measure portability. As expected, interoperability during reviewing patient medical history process is the strongest indicator.

Data availability itself is perceived as an important EHR system characteristic, but it is expected to be portable as well, else the availability is limited. The path loading of 0.186 across all stakeholders supports the hypothesis and can be generalized that perceived expected satisfaction with availability of EHR systems is positively associated with perceived expected satisfaction with portability of EHR systems.

All four stakeholder groups examined in this study also exhibited the positive correlation between the perceived expected satisfaction with availability of EHR systems on the perceived expected satisfaction with portability of EHR systems. While there are varying expectations from an information system in the healthcare industry across stakeholders, they all agree that their perceived data availability is positively associated with perceived portability. They proved to be important attributes of a system to provide an interconnected and interoperable system that provides the required information to the user.

There is a high degree of correlation between satisfaction with availability and satisfaction with portability. This correlation could be explained by stakeholders reporting that information is available because it has been made portable either in location or device.

The success of an EHR system implementation is measured by the degree it is used (e.g., Devaraj \& Kohli, 2003) because it meets the users' expectations. Kirsch (1997) found that the alignment of the interests of multiple stakeholders during the implementation process helped to achieve the desired outcome. Furthermore, involving users in the system development and deployment process is found to promote IS project performance and user satisfaction (Jiang, Klein, \& Carr, 2006). The findings of this study support the EHR system implementation success by considering the multi-stakeholder user requirements regarding the EHR availability and EHR portability. Furthermore, our study helps to find the exact activity and stakeholder group who indicate the strongest expectations of satisfaction with a particular system characteristic. This finding is especially important to mitigate software development and implementation risks.

\section{Conclusion}

Information systems in the healthcare domain support varying stakeholder groups across the patient care process. In order to increase safety and make decisions for patient care, access to timely and relevant information about the patients' conditions and their medical history is imperative. Data availability and portability are important system characteristics in the healthcare domain to support proper and safe care. 
This study empirically investigated and found that perceived expected satisfaction with data availability leads to perceived expected satisfaction with portability. Satisfaction was measured by data access and efficiency, while portability was measured by interconnectedness and interoperability of a system. Satisfaction with available data for stakeholders to perform their job functions directly related to satisfaction with the information sharing of the connected data sources.

We investigated the perceived expectations with availability and portability EHR system characteristic on a granular level. The patient flow activates were grouped in four major process sequence blocks across four stakeholder groups. Empirical data of self-reported perceived satisfaction with EHR system availability and portability was analyzed using factor analysis to identify the "intercorrelated" observed indicators, which load under a common factor (Field, 2000, p. 424). Principal component analysis (PCA) method was employed to extract the factors, and then we performed a varimax (orthogonal) rotation (Gorsuch, 1983, p. 205). Cronbach Alpha of 0.866 indicated a high level of internal consistency while the items loaded together measuring the same construct indicated construct validity.

Walls et al.'s (1992) ISDT provided the theoretical rigor to perform meta-analysis and identify meta-requirements on the organizational and system level. Our findings add to the existing literature both theoretically and practically. Theoretically we expand the literature with the more granular understanding of patient care processes and the perceived satisfaction with EHR data availability and portability across multiple stakeholder groups. Practical implications provide guidance for finding the particular process or stakeholder group with particular expectations from the system in regards to data availability and portability.

Software vendors and project executives may use the results of this study to enhance their understanding of stakeholder needs in regards to expected satisfaction with data availability on a granular level, including processes, activities, and stakeholders. It is especially important to consider the indicator variations among stakeholder role and patient flow processes. It can help software vendors to design a better suited software for all stakeholder groups, while these findings allow project executives to select the best software to support the different stakeholder groups.

\section{Limitations and Future Directions}

This research is limited in scope and not free of shortcomings. These limitations may provide directions for future research within and beyond the domain of this study. Information was collected through a survey from a sufficient sample population representing each stakeholder group. However, due to the large number of variables observed, exploratory factor analysis may have experienced 'underfactoring', where large enough discrepancies between the model and data may not be significant (Humphreys \& Montanelli, 1975). Consequently, the model fit in CFA had to follow a more relaxed cut off values but within the literature suggested limits. Future studies may want to consider smaller number of variables or increase the sample population.

Similarly, CFA was performed on a simplified model to test the hypothesis on the stakeholder level due to decreased sample size once stakeholder role was used as a grouping variable. It would be preferred to run the model in its entirety while observing estimates on the region level. The strength of the indicator variables and the variation of path coefficient intensities clearly indicate the expectations across stakeholder groups within the hypothesis.

The collected information on regions was not utilized, which might have provided further direction on expectations from stakeholders based on the region they operate. It is an interesting objective to test whether regional regulations influence stakeholders' expectations from an EHR system characteristic. It can be the focus of a future research itself. Additionally, due to the same reason, the study was unable to capitalize on the different healthcare institution types, from which 
data was collected. Comparing stakeholders' expectations across institution types may also reveal unique expectations from an HER system.

As the moderating effect of stakeholder role was explored, some path coefficients revealed surprising magnitude. It would be worthwhile to investigate the underlying reason behind it and whether it is correlated to regions of the institute type from where data was collected.

Following the approach of this study, the relationship between the other variables will also be investigated and stakeholders will be considered as moderators.

\section{References}

Aarts, J., \& Peel, V. (1999). Using a descriptive model of change when implementing large scale clinical information systems to identify priorities for further research. International Journal of Medical Informatics, 56(1-3), 43-50.

Ahn, J. H., \& Skudlark, A. E. (1997). Resolving conflict of interests in the process of an information system implementation for advanced telecommunication services. Journal of Information Technology, 12, 3-13.

Al-Khaldi, M. A., \& Wallace, R. S. O. (1999). The influence of attitudes on personal computer utilization among knowledge workers: The case of Saudi Arabia. Information \& Management, 31, 185-204.

Ancker, J. S., Edwards, A. M., \& Miller, M. C. (2012). Consumer perceptions of electronic health information exchange. American Journal of Preventive Medicine, 43, 76-80.

Bailey, J. E., \& Pearson, S. W. (1983). Development of a tool for measuring and analyzing computer user satisfaction. Management Science, 29(5), 530-545.

Baskerville, R., \& Siponen, M. (2002). An information security meta-policy for emergent organizations. Journal of Logistics Information Management, special issue on Information Security, 15(5-6), 337346.

Bates, D. W., Cohen, M., Leape, L. L., Overhage, J. M., Shabot, M. S., \& Sheridan, T. (2001). Reducing the frequency of errors in medicine using information technology. Journal of the American Medical Informatics Association, 8(4), 299-308.

Baumgartner, H., \& Hombur, C. (1996). Applications of structural equation modeling in marketing and consumer research: A review. International Journal of Research in Marketing, 13, 139-161.

Berg, M. (2001). Implementing information systems in health care organizations: Myths and challenges. International Journal of Medical Informatics, 64(2-3), 143-156.

Bergman, O., Beyth-Marom, R., \& Nachmias, R. (2008). The user-subjective approach to personal information management systems design: Evidence and implementations. Journal of the American Society for Information Science and Technology, 59(2), 235-246.

Bingi, P., Sharma, M. K., \& Godla, J. K. (1999). Critical issues affecting an ERP implementation. Information Systems Management, 16, 7-14.

Brooke, J. (1996). SUS: A quick and dirty usability scale. In P. W. Jordan, B. Thomas, B. A. Weerdmeester, \& I. L. McClelland (Eds.), Usability evaluation in industry (pp. 189-194). London, UK: Taylor \& Francis.

Browne, M. W., \& Cudeck, R. (1993). Alternative ways of assessing model fit. In K. A. Bollen \& J. S. Long (Eds.), Testing structural equation models (pp. 136-162). Beverly Hills, CA: Sage Publications.

Burn, J. M., \& Ash, C. G. (2005). A dynamic model of e-business strategies for ERP enabled organizations. Industrial Management \& Data Systems, 105(8), 1084-1095.

Carr, S. C. (1992). A primer on the use of Q sort technique factor analysis. Measurement and Evaluation in Counseling and Development, 25, 133-138. 
Chin, H. L., \& Krall, M. (1997). Implementation of a comprehensive computer-based patient record system in Kaiser Permanente's Northwest Region. MD Computing: Computers in Medical Practice, 14(1), $41-45$.

Chin, H. L., \& McClure, P. (1995). Evaluating a comprehensive outpatient clinical information system: A case study and model for system evaluation. Proceedings for the Annual Symposium of Computer Application on Medical Care, 717-721.

Code of Federal Regulations - U.S. Code Title 44 Chapter 35 Subchapter III $\S 3542$ C

Corvera Charaf, M., Rosenkranz, C., \& Holten, R. (2013). The emergence of shared understanding: Applying functional pragmatics to study the requirements development process. Information Systems Journal, 23(2), 115-135.

David, J. (2002). Policy enforcement in the workplace. Computers and Security, 21(6), 506-513.

Davis, F. D. (1989). Perceived usefulness, perceived ease of use, and user acceptance of information technology. MIS Quarterly, 13, 319-340.

Davis, F. D. (1993). User acceptance of information technology system characteristics, user perceptions and behavioral impacts. International Journal of Man-Machine Studies, 38, 475-487.

DeLone, W. H., \& McLean, E. R. (1992). Information systems success: The quest for the dependent variable. Information Systems Research, 3(1), 60-95.

Devaraj, S., \& Kohli, R. (2003). Performance impacts of information technology: Is actual usage the missing Link? Management Science, 49, 273-289.

DeVellis, R. F (2003). Scale development: Theory and applications (2nd ed.). Thousand Oaks, CA: Sage Publications.

Dhillon, G., \& Backhouse, J. (2001). Current directions in IS security research: Toward socioorganizational perspectives. Information Systems Journal, 11(2), 127-153.

Dimitropoulos, L., Patel, V., \& Scheffler, S. A. (2011). Public attitudes toward health information exchange: Perceived benefits and concerns. The American Journal of Managed Care, 17, 111-116.

Dix, A., Finlay, J., Abowd, G., \& Beale, R. (1993). Human-computer interaction. New Jersey: PrenticeHall.

Dorr, D. A., Jones S. S., \& Wilcox A. (2007). A framework for information system usage in collaborative care, Journal of Biomedical Informatics, 40, 282-287.

Field, A. (2000). Discovering statistics using SPSS for Windows. London - Thousand Oaks - New Delhi: Sage Publications.

Fox, S. (2000). The online health care revolution: How the web helps Americans take better care of themselves. Washington, DC: The Pew Internet \& American Life Project.

Gorsuch, R. L. (1983). Factor analysis (2nd ed.). Hillsdale, NJ: Lawrence Earlbaum Associates.

Greenhalgh T., Stramer K., Bratan T., Byrne E., Russell J., Hinder S., \& Potts H. (2010). Adoption and non-adoption of a shared electronic summary record in England: A mixed method case study. British Medical Journal, 340, 3111.

Hair, J. F., Jr., Anderson, R. E., Tatham, R. L., \& Black, W. C. (1998). Multivariate data analysis (5th ed.). Upper Saddle River, NJ: Prentice Hall.

Hair, J. F., Jr., Black, W. C., Babin, B. J., \& Anderson, R. E. (2010). Multivariate data analysis (7th ed.). Upper Saddle River, New Jersey: Pearson Education International.

Hamilton, S., \& Chervany, N. L. (1981). Evaluating information system effectiveness - Part I: Comparing evaluation approaches. MIS Quarterly, 5(3), 55-69.

Heeks, R. (2006). Health information systems: Failure, success and improvisation. International Journal of Medical Informatics, 75(2), 125-137. 
Henderson, R. D., Smith, M. C., Podd, J., \& Varela-Alvarez, H. (1995). A comparison of the four prominent user-based methods for evaluating the usability of computer software. Ergonomics, 10, 20302044.

Humphreys, L. G., \& Montanelli, R. G., Jr. (1975). An investigation of the parallel analysis criterion for determining the number of common factors. Multivariate Behavioral Research, 10(2), 193-205.

Igbaria, M. (1990). End-user computing effectiveness: A structural equation model. OMEGA International Journal of Management Science, 18(6), 637- 652.

Institute of Electrical and Electronics Engineers. (1990) IEEE Standard Computer Dictionary: A Compilation of IEEE Standard Computer Glossaries, New York, NY.

ISO DIS 9241-210 (2008). Ergonomics of human-system interaction - Part 210: Human-centred design process for interactive systems. ISO.

ISO/TR 20514:2005, Health informatics — Electronic Heath Record - Definition, Scope, Context (n.d.). ISO. Retrieved from https://www.iso.org/obp/ui/\#iso:std:iso:tr:20514:ed-1:v1:en

Jiang, J., Klein, G., \& Carr, C. (2002). Measuring information systems service quality: SERVQUAL from the other side. MIS Quarterly, 26(2), 145-166.

Joss, R., \& Kogan M. (1995). Advancing quality: Total quality management in the National Health Service. Buckingham: Open University Press.

Kaplan, B., \& Harris-Salamone, K. (2009). Health IT success and failure: Recommendations from literature and an AMIA workshop. Journal of the American Medical Informatics Association, 16(3), 291-299.

Kirsch, L. J. (1997). Portfolios of control modes and IS project management. Information Systems Research $8(3), 215-239$.

Kline, R. B. (2005). Principles and practice of structural equation modeling (2nd ed.). New York: Guildford.

Kline, R. B. (2010). Principles and practice of structural equation modeling (3rd ed.). New York: Guilford Press.

Kohn, L. T., Corrigan, J. M., \& Donaldson, M. S. (Eds.). (2000). To err is human: Building a safer health system. Committee on Quality of Health Care in America, Institute of Medicine: National Academies Press.

Kumar, A., \& Segev, A. (1993).Cost and availability tradeoffs replicated data concurrency control. $A C M$ Transactions on Database Systems, 18(1), 102-131.

Laplante, P. A., \& Ovaska, S. J. (2011). Real-time systems design and analysis: Tools for the practitioner (4th ed.). Wiley-IEEE Press.

Lawler, F., Cacy, J. R., Viviani, N., Hamm, R. M., \& Cobb, S. W. (1996). Implementation and termination of a computerized medical information system. Journal of Family Practice, 42(3), 233-236.

Leape, L. L., Bates, D. W., \& Culen, D. J. (1995). Systems analysis of adverse drug events, Journal of the American Medical Association, 274(1), 34-43.

Lewis, J. R., \& Sauro, J. (2009). The factor structure of the system usability scale. Proceedings of the Human Computer Interaction International Conference (HCII 2009), San Diego CA, USA.

McGlynn, E. A. (1997). Six challenges in measuring the quality of health care. Health Affairs, 16, 7-21.

McGowan, J. J., Cusack, C. M., \& Poon, E. G. (2008). Formative evaluation: A critical component in EHR implementation. Journal of American Medical Association, 15(3), 297-301.

Meijden, M. J., Tange, H. J., Troost, J., \& Hasman A. (2003). Determinants of success of inpatient clinical information systems: A literature review. Journal of American Medical Informatics Association, 10(3), $235-243$. 
Murff, H. J., \& Kannry, J. (2001). Physician satisfaction with two order entry systems Journal of the American Medical Informatics Association, 8(5), 499-509.

Nielsen, J. (1994). Usability engineering. Boston: Academic Press.

Ornstein, S., \& Bearden, A. (1994). Patient perspectives on computer-based medical records. Journal of Family Practice, 38, 606-610.

Oz, E., \& Sosik, J. J. (2000). Why information systems projects are abandoned: A leadership and communication theory and exploratory study. Journal of Computer Information Systems, 41(1), 66-79.

Padhy, R. P., Patry, M. R., \& Satapathy, S. C. (2011). Cloud computing: security issues and research challenges IRACST. International Journal of Computer Science and Information Technology \& Security (IJCSITS), 1(2), 136-146.

Pan, G. (2005). Information systems project abandonment: A stakeholder analysis. International Journal of Information Management, 25(2), 173-184.

Panian, Z. (2009). Recent advances in data management. WSEAS Transactions on Computers, 9(7), 10611071.

Radhakrishna, K., Goud, B. R., Kasthuri, A., Waghmare, A., \& Raj, T. (2014). Electronic health records and information portability: A pilot study in a rural primary healthcare center in India. Perspectives in Health Information Management, 11(1b).

Razi, M. L., Athappilly, K., \& Rea, A. (2009). The Community Health Information System (CHIS): Delivering web-based customized healthcare using an AI-infused expert system. International Journal of Electronic Healthcare, 5(3), 303-325.

Ridsdale, L., \& Hudd, S. (1994). Computers in the consultation: The patient's view. British Journal of General Practice, 44, 367-369.

Sallas, B., Lane, S., Mathews, R., Watkins, T., \& Wiley-Patton, S. (2007). An iterative assessment approach to improve technology adoption and implementation decisions by healthcare managers. Information Systems Management, 24, 43-57.

Shi, L., \& Singh, D. A. (2008). Delivering health care in America: A systems approach (4th ed.). Jones \& Bartlet Publishers.

Simon, P. (2010). How not to run an IT project: A case study. Business Intelligence, (10)1, 1-17.

Srinivasan, A. (1985). Alternative measures of system effectiveness: Associations and implications. MIS Quarterly, 9(3), 243-253.

Szajna, B., \&Scamell, R. W. (1993). The effects of information system expectations on their performance and perceptions. MIS Quarterly, 17, 493-516.

Thornewill, J., Dwling, A. F., Cox, B. A., \& Esterhazy, R. J. (2011). Information infrastructure for consumer health: A health information exchange stakeholder study. American Journal of Preventative Medicine, 40(5), 123-133.

Tierney, W. M., Miller, M. E., Overhage, J. M., \& McDonald, C. J. (1993). Physician inpatient order writing on microcomputer workstations. Effects on resource utilization. The Journal of the American Medical Association, 269(3), 379-383.

Vaast, E., \& Levina, N. (2006). Multiple faces of codification: Organizational redesign in an IT organization. Organization Science, 17(2), 190-201.

Venkatesh, V. (2000). Determinants of perceived ease of use: Integrating control, intrinsic motivation, and emotion into the technology acceptance model. Information System Research, 11, 342-65.

Venkatesh, V., Speier, C., \& Morris, M. G. (2002). User acceptance enablers in individual decision making about technology: Toward an integrated model. Decision Sciences, 33, 297-316. 
Walls, J., Widmeyer, G., \& El Sawy, O. (1992). Building an information system design theory for vigilant EIS. Information Systems Research, 3(1), 36-59.

Zhang, L., Lee, M. K. O., Zhang, Z., \& Banerjee, P. (2003). Critical success factors of enterprise resource planning systems implementation success in China. Proceedings of the 36th Hawaii International Conference on System Sciences (HICCS), Track 8, p.236. doi: 10.1109/HICSS.2003.1174613

\section{Appendix}

Meta-analysis of system features

\begin{tabular}{|l|l|}
\hline \multicolumn{1}{|c|}{ System Meta-Kernels } & \multicolumn{1}{|c|}{$\begin{array}{c}\text { Kernel } \\
\text { Characteristics }\end{array}$} \\
\hline \multicolumn{1}{|c|}{ Availability } & Effectiveness \\
Choefel 2003 & Efficiency \\
Bevan et al. 1991 & Satisfaction \\
Rengger 1991 & Data Access \\
Peterson et al. 2005 & \\
\hline \multicolumn{1}{|c|}{ Portability } & Interoperabillity \\
Tange et al. 2006 & Interconnectedness \\
Laitinen et al. 2000 & Transparency \\
Bates et al. $2001 ;$ Leape et al. 199 & \\
\hline \multicolumn{1}{|c|}{ Security/Accountability } & Confidentiality \\
Win et al. 2002 & Data Integrity \\
Huston 2001 & Responsibility \\
Chao et al. 2005 & Auditability \\
Peterson et al. 2005 &
\end{tabular}

\section{Biographies}

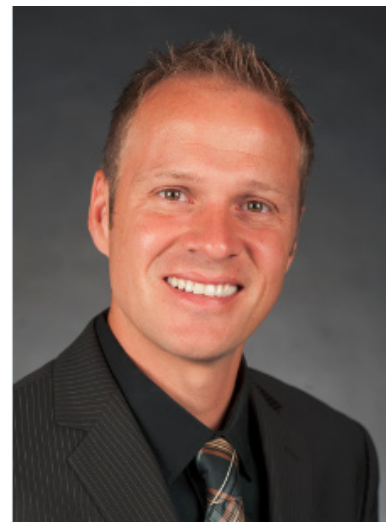

Karoly Bozan (Ph.D.) is an Assistant Professor of Informatics and Computer Science at Idaho State University. Dr. Bozan's research interest encompasses system design in the health domain in the multistakeholder context.

Prior to joining academia, Dr. Bozan held numerous technical and management consulting positions in a variety of industries. 


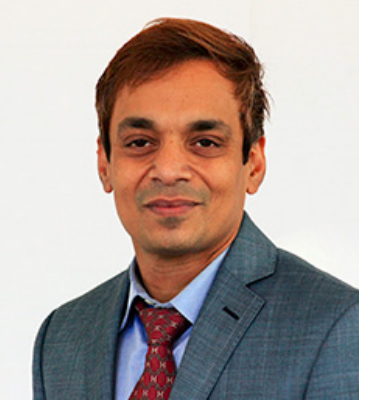

Pratim Datta (Ph.D.) is a two-time Farris Family Research Innovation Fellow and an Associate Professor of IS and Supply Chains at Kent State University. Ranked among the top 40 researchers internationally, Datta has over 55 journal articles and conference proceedings with multiple best paper awards. Datta focuses on IS and supply chain use, performance and security as well as cross-functional corporate decision-making. He has won the Paul Pfeiffer Professional and Teaching Award. He has also received the Outstanding MBA Professor Award and he is the showcased professor for the Executive MBA Program.

Prior to joining academia in 2005, Datta worked as a senior project manager and corporate strategy consultant for IBM Global Services, SAP and Price Waterhouse Coopers. He is the founder and director of SCITS (Supply Chain and IT Strategy), a collaborative research hub panning industry and academia. 